\title{
Clinical presentation of thyroid dysfunction and Addison's disease in young adults with type 1 diabetes
}

King Sun Leong, Maureen Wallymahmed, John Wilding, Ian MacFarlane

\begin{abstract}
Summary
In a clinic population of 509 type 1 diabetic patients aged $16-45$ years, $5.5 \%$ had received treatment for thyroid disorders (20 hypothyroid, three males; eight thyrotoxicosis, four males), and Addison's disease was present in four patients $(0.8 \%$, one male). In all patients, type 1 diabetes preceded the diagnosis of the other autoimmune disorder. The clinical presentation of hypothyroidism was usually insidious with few symptoms, although an increased frequency of hypoglycaemic symptoms and/or raised serum cholesterol levels often prompted thyroid function testing. In contrast, the patients with thyrotoxicosis had florid symptoms, weight loss (mean $8.12 \mathrm{~kg}$ ), palpable goitres, increasing insulin requirements, and low cholesterol levels. Six patients did not achieve remission or had recurrent thyrotoxicosis after oral antithyroid treatment and required ${ }^{131} I$ or thyroid surgery. A family history of autoimmune disease was present in $25 \%$ of patients with thyroid disorders (seven thyrotoxic and one hypothyroid) and in three of the four patients with Addison's disease. In this population of young adult type 1 diabetic patients, appropriate tests for thyroid dysfunction and Addison's disease should be carried out if there is clinical suspicion and/or unexplained changes in diabetic metabolic control or serum cholesterol. Careful follow-up of patients with a family history of these conditions is recommended.
\end{abstract}

Keywords: hypothyroidism; thyrotoxicosis; Addison's disease; diabetes; autoimmune disorders

The development of thyroid dysfunction or Addison's disease in a patient with type 1 diabetes can cause major disturbances in diabetic metabolic control and these conditions need prompt diagnosis and appropriate treatment. Autoimmune conditions, including thyroid disorders and Addison's disease, have been reported to occur more frequently in patients with type 1 diabetes than in the non-diabetic population. ${ }^{1}$ However, the prevalence of autoimmune thyroid dysfunction (AITD) in type 1 diabetes varies with different racial groups, age groups and geographical regions, and can range from $7 \%$ to as much as
$24 \% .^{2-5}$ The few studies in the UK have been performed on a wide age range (10-90 years) of mixed type 1 and type 2 patients. ${ }^{467}$ We therefore assessed the clinic prevalence of thyroid disease and Addison's disease in a young adult type 1 diabetic population ( $<45$ years) in North Liverpool and examined the mode of presentation of these disorders to identify features that could help with early diagnosis.

\section{Patients and methods}

The clinic database was examined to identify all type 1 diabetic patients under the age of 45 years who had attended the young adult diabetes clinic over a 6-year period from 1991 to 1997 . All patients had information taken at each clinic attendance with regard to concurrent and previous thyroid illness/treatment (oral antithyroid treatment, thyroid surgery or ${ }^{131}$ I therapy) and/or Addison's disease/ treatment. This database was updated at each clinic attendance. Patients receiving treatment for thyroid dysfunction (including those with subclinical hypothyroidism taking thyroxine replacement) and Addison's disease were identified. The case notes of these patients were examined to identify signs and symptoms leading to the diagnosis of AITD and Addison's disease. From the database, the following information was obtained when first recorded: age of patient, age at diagnosis of thyroid disorder/Addison's disease, age at diagnosis of diabetes, cholesterol and HbA1c levels.

CLINIC SCREENING POLICY FOR AITD AND ADDISON'S DISEASE 1991-7

All patients with type 1 diabetes had their serum thyroid-stimulating hormone (TSH) checked at least once when first attending the clinic. If the TSH was abnormal the complete thyroid profile, including free thyroxine $\left(\mathrm{FT}_{4}\right)$ and tri-iodothyronine $\left(\mathrm{FT}_{3}\right)$ was also checked. A family history of endocrine disease was also obtained. Thyroid antibodies (microsomal and thyroglobulin) were not routinely checked except in those with subclinical hypothyroidism (raised $\mathrm{TSH}$, normal $\mathrm{FT}_{4}$ and $\mathrm{FT}_{3}$ ). If antibodies were positive and repeat TSH was elevated, thyroxine was commenced. ${ }^{8}$

STATISTICAL TESTS

Data are presented as means $( \pm S D)$. The results were analysed using paired $t$-tests. 
Table 1 Demographic data of 509 type 1 diabetic patients studied

\begin{tabular}{|c|c|c|c|c|c|c|c|c|c|}
\hline & Number & $\begin{array}{l}\text { Mean age } \\
\text { (years) } \pm S D\end{array}$ & $\begin{array}{l}\text { Mean duration } \\
\text { of IDDM } \\
\text { (years) } \pm S D\end{array}$ & $\begin{array}{l}\text { Mean } H b A_{1 c} \\
(\%) \pm S D\end{array}$ & $\begin{array}{l}\text { Number with } \\
\text { AITD (\%) }\end{array}$ & $\begin{array}{l}\text { Number with } \\
\text { Addison's } \\
\text { disease (\%) }\end{array}$ & $\begin{array}{l}\text { Median age at } \\
\text { diagnosis of } \\
\text { hypothyroidism } \\
\text { (range) (years) }\end{array}$ & $\begin{array}{l}\text { Median age at } \\
\text { diagnosis of } \\
\text { thyrotoxicosis } \\
\text { (range) (years) }\end{array}$ & $\begin{array}{l}\text { Median age at } \\
\text { diagnosis of } \\
\text { Addison's } \\
\text { (range) (years) }\end{array}$ \\
\hline Males & 301 & $30.3 \pm 8.0$ & $10.9 \pm 8.1$ & $8.8 \pm 8.1$ & $7(2.3 \%)$ & $1(0.3 \%)$ & $35 \quad(17-39)$ & $31(19-34)$ & $16 \quad(16)$ \\
\hline Females & 208 & $28.2 \pm 8.2$ & $12.4 \pm 8.5$ & $9.1 \pm 2.1$ & $21(10.1 \%)$ & $3(1.4 \%)$ & $30 \quad(10-45)$ & $29(21-43)$ & $21 \quad(20-42)$ \\
\hline Total & 509 & $29.4 \pm 8.1$ & $11.2 \pm 8.3$ & $8.9 \pm 2.1$ & $28(5.5 \%)$ & $4(0.8 \%)$ & $32.5(10-45)$ & $31(19-43)$ & $20.5(16-42)$ \\
\hline
\end{tabular}

Statistical significance was assumed at the $\mathrm{p}<0.05$ level.

\section{Results}

During the 6 years covered by the study, 509 type 1 diabetic patients (301 males, 208 females) aged between 16-45 years (table 1) attended the young adult diabetes clinic. All were Caucasians except three who were of Indian origin. There were 32 patients who were receiving treatment for either thyroid dysfunction (28) or Addison's disease (four). At the start of the study, five patients (all females) were identified as having concurrent thyroid disease. Over the 6-year study period, 23 further cases (seven males) of thyroid dysfunction were identified, averaging about four cases per year.

PATIENTS WITH THYROID DYSFUNCTION

Of the 28 patients with thyroid disorders, 20 were receiving thyroxine for hypothyroidism (three males) and eight had been treated for thyrotoxicosis (four males). All patients were diagnosed with thyroid disease after the development of type 1 diabetes. Thyroid antibodies were not routinely checked. Six thyrotoxic patients had thyroid antibodies checked and all were positive for thyroid microsomal antibodies (normal range 0-73 IU/ml). Six hypothyroid patients had thyroid antibodies checked and five were positive for thyroid microsomal antibodies.

PRESENTATION OF THYROTOXICOSIS

No patient was diagnosed by thyroid function test screening at entry to the clinic. All eight subsequently developed florid symptoms (palpitations, sweating, heat intolerance, weight loss) and palpable goitres which prompted further tests. Six patients had weight loss (mean $8.1 \pm 3.4 \mathrm{~kg}$ over 6 months) and three male patients developed psychoses as a result of the thyrotoxicosis and required psychotropic medication. Increases in insulin requirement were seen in six patients and a reduction in serum cholesterol was observed in four patients in the months preceding the diagnosis of hyperthyroidism. Six patients did not achieve remission or had recurrent thyrotoxicosis after at least 6 months of carbimazole therapy and were subsequently treated with radioiodine (five) and partial thyroidectomy (one).

\section{PRESENTATION OF HYPOTHYROIDISM}

In contrast to patients with thyrotoxicosis there were usually few signs and symptoms in the 20 patients with hypothyroidism. Screening with thyroid function tests at entry into the clinic revealed only one patient with a raised $\mathrm{TSH}$ and normal $\mathrm{FT}_{4}$ levels. All the other thyroid function tests were performed in response to patients' symptoms and/or raised serum cholesterol results. The signs and symptoms were mild: eight patients had difficulty with achieving weight loss, eight had recurrent hypoglycaemic symptoms, two had palpable goitres and two complained of tiredness. As a result of the tests, two patients were found to have subclinical hypothyroidism with raised thyroid antibodies and the rest of the patients had hypothyroidism.

$\mathrm{HbA}_{1 \mathrm{c}}$ AND SERUM CHOLESTEROL AT DIAGNOSIS OF THYROID DISORDER

Seventeen patients with AITD had $\mathrm{HbA}_{1 \mathrm{c}}$ measurements at diagnosis of the thyroid disorder (10 hypothyroid) and 12 months later after treatment (table 2). Mean $\mathrm{HbA}_{1 \mathrm{c}}$ at diagnosis of the thyroid disorder was $9.8 \%$ and had improved significantly 12 months later to $7.8 \%$ $(\mathrm{p}=0.0019)$.

Thirteen patients (nine hypothyroid) had cholesterol levels checked at diagnosis and 12 months after treatment of the thyroid disorder (table 2). These patients were not on lipidlowering agents. In the thyrotoxic group, mean cholesterol levels were low at diagnosis (3.3 $\mathrm{mmol} / \mathrm{l})$ and increased after treatment (4.8 $\mathrm{mmol} / \mathrm{l} ; \mathrm{p}=0.052)$. In the hypothyroid group, mean cholesterol levels were raised at diagnosis $(6.19 \mathrm{mmol} / \mathrm{l})$ and improved significantly 12 months after treatment $(5.5 \mathrm{mmol} / \mathrm{l}$; $\mathrm{p}=0.0003$ ).

Table $2 \mathrm{HbA}_{1 \mathrm{c}}$ and serum cholesterol in patients with thyroid dysfunction before and 12 months after treatment (analysed by paired t-test)

\begin{tabular}{|c|c|c|c|c|c|c|}
\hline & $\begin{array}{l}\text { Mean } H b A_{1 c}(\%) \text { at } \\
\text { diagnosis } \pm S D \\
(n=17)\end{array}$ & $\begin{array}{l}\text { Mean } \mathrm{Hb}_{1 c} \\
(\%) \text { after } \\
\text { treatment } \pm S D \\
(n=17)\end{array}$ & $p$ value & $\begin{array}{l}\text { Mean cholesterol } \\
\text { (mmol/l) at diagnosis } \\
\pm S D(n=13)\end{array}$ & $\begin{array}{l}\text { Mean cholesterol } \\
(\text { mmol/l) after } 2 \\
\text { months after treatment } \\
\pm S D(n=13)\end{array}$ & $p$ value \\
\hline Hypothyroid & $9.3 \pm 1.4$ & $7.8 \pm 0.8$ & 0.031 & $6.2 \pm 1.1$ & $5.5 \pm 0.9$ & 0.0003 \\
\hline Hyperthyroid & $10.6 \pm 2.8$ & $8 . \pm 1.2$ & 0.076 & $3.3 \pm 1.0$ & $4.8 \pm 1.2$ & 0.052 \\
\hline
\end{tabular}


ADDISON'S DISEASE

Four patients (one male) had Addison's disease. These patients presented with Addison's disease within 3 years after diagnosis of type 1 diabetes at ages 20,21, 42 (females) and 16 years (male). Three patients presented to casualty with Addisonian crises. The other patient presented in clinic with a 3-month history of tiredness, weight loss and increasing pigmentation. Three patients with Addison's disease had adrenal and thyroid antibodies measured. Adrenal antibodies were positive in two females; one of whom also had thyroid antibodies but was biochemically euthyroid. The third patient (male) did not have adrenal or thyroid antibodies.

FAMILY HISTORY

Eight $(29 \%)$ of the patients with thyroid disorders (seven thyrotoxic, one hypothyroid) had a family history of thyroid disease (first and second degree relatives) and three out of four patients with Addison's disease had a family history of Addison's disease in first degree relatives.

\section{Discussion}

This study of young adult Caucasian subjects with type 1 diabetes establishes the clinic prevalence for treated thyroid disorders as $5.5 \%$ (hypothyroid 3.9\%, thyrotoxicosis $1.6 \%$ ). In all cases, the diagnosis of diabetes preceded the diagnosis of thyroid or Addison's disease.

In the UK general population, the prevalence of thyroid disease has been reported to be around $5 \%$ in subjects of all age groups, including patients with diabetes, ${ }^{9-10}$ with equal numbers of hyper- and hypothyroidism. A study from Scotland reported a rate of $20.4 \%$ for hypothyroidism and $7.5 \%$ for thyrotoxicosis among their type 1 patients. ${ }^{4}$ However, the ages ranged from 10 to 89 years in that study and the prevalence of thyroid disorders increases with age in diabetic patients and peaks at $60-70$ years. $^{11}$

In our patients, there were few typical signs and symptoms of hypothyroidism at diagnosis. Clues to the diagnosis were mildly raised cholesterol levels, recurrent hypoglycaemic symptoms and the inability to lose weight in those who were overweight. Most of these patients were detected by thyroid function tests in response to these complaints and/or for a raised serum cholesterol. Thyroxine replacement in these patients improved glycaemic control, probably by reducing the number of hypoglycaemic episodes and therefore the swings in blood glucose. The thyrotoxic patients, however, had classical signs and symptoms of thyrotoxicosis. There was weight loss, heat intolerance or palpable goitres in all patients; furthermore insulin requirements were rising, cholesterol levels were low and psychosis developed in three male patients. This florid presentation was in contrast to the observation that teenagers with type 1 diabetes and

\section{Summary points}

Consider co-existing thyroid and/or Addison's disease in patients with type I diabetes and unexplained changes in weight, serum cholesterol, insulin requirements and glycaemic control, particularly those with a family history of thyroid and/or Addison's disease. These patients need careful follow-up

thyrotoxicosis may present insidiously. ${ }^{12} \mathrm{Six}$ patients did not achieve remission with carbimazole and required either radioiodine therapy (five) or partial thyroidectomy (one). Thyroid antibody tests were not routinely performed in our patients and it is therefore possible that some patients with palpable goitres had Hashimoto's thyroiditis rather than primary hypothyroidism.

Cholesterol levels significantly increased in thyrotoxic type 1 diabetic patients and decreased in hypothyroid patients after 12 months treatment of the thyroid disorder. $\mathrm{HbA}_{1 \mathrm{c}}$ values improved significantly in both groups over the same time period. The development of thyrotoxicosis in our patients occurred after the onset of type 1 diabetes, in contrast to an American study where thyrotoxicosis preceded or coincided with the development of type 1 diabetes in the majority of their patients. ${ }^{13}$

Addison's disease was present in four $(0.8 \%)$ of our type 1 diabetic patients, compared with a prevalence rate of $0.01 \%$ in the UK general population. ${ }^{14}$ The prevalence of adrenal antibodies in type 1 young adult diabetic patients in the UK is unknown, although in a US paediatric type 1 diabetic population $1.5 \%$ had positive adrenal antibodies, ${ }^{15}$ and in 239 Italian type 1 diabetic patients (aged 2-67 years) 4\% had positive adrenal antibodies. ${ }^{16}$ All our patients with Addison's disease presented within 3 years of diagnosis of type 1 diabetes. One of these, a male patient, had no family history of Addison's disease and presented with an Addisonian crises. In one patient with a family history of Addison's disease, the diagnosis was made and treated before an Addisonian crises occurred.

In conclusion, this survey suggests that a family history for autoimmune conditions should be obtained in all type 1 diabetic patients. It would also be worthwhile updating the family history at annual review. If a positive family history is obtained a high index of suspicion for thyroid dysfunction and Addison's disease should be maintained. Any patient with unexplained changes in weight, serum cholesterol, insulin requirements and glycaemic control should also be tested for autoimmune disorders. A low threshold for checking thyroid function tests and/or synacthen tests in young type 1 diabetic patients is essential to detect these co-existing autoimmune conditions. 
1 MacFarlane IA. Endocrine diseases and diabetes mellitus. In: Pickup J, Williams G, eds, Textbook of diabetes, 2 nd edn. Blackwell Science Ltd, 1997; pp 64.1-64.20.

2 Gruneiro De Papendieck L, Chiesa A, Trifone L, Bergada I, Raizman H, Bergada C. Thyroid disorders in children and adolescents with insulin dependent diabetes mellitus. Acta Pediatr Esp 1995;53:362-5.

3 Gamba S, Carlini M, Blatto A, et al. Frequency of autoimmune thyroid disease in adult patients with insulin dependent diabetes mellitus. Giornale Ital Diabetol 1994;14: $101-5$.

4 Perros P, McCrimmon RJ, Shaw G, Frier BM. Frequency of thyroid dysfunction in diabetic patients: Value of annual screening. Diabet Med 1995;12:622-7.

5 McKenna MJ, Herskowitz R, Wolfsdorf JI. Screening for thyroid disease in children with IDDM. Diabetes Care 1990; 13:801-3.

6 Feely J, Isles TE. Screening for thyroid dysfunction in diabetics. BMF 1979;1:1678.

7 Smithson MJ. Screening for thyroid dysfunction in a community population of diabetic patients. Diabet Med 1998;15:148-50.

8 Anon. Managing subclinical hypothyroidism. Drugs Therapeut Bull 1998;36:1-3.

9 Tunbridge WMG, Evered DC, Hall R, et al. The spectrum of thyroid disease in a community: the Whickham Study. Clin Endocrinol 1977;7:481-93.
$10 \mathrm{McGregor}$ AM. The thyroid gland and disorders of thyroid function. In: Weatherall DJ, Ledingham JGG, Warrell DA, eds, Oxford textbook of medicine, 3rd edn. Oxford: Oxford University Press, 1996; pp 1603-18.

11 Whittingham S, Mathews JD, Mackay IR, Stocks AE, Ungar B, Martin FIR. Diabetes mellitus, autoimmunity and ageing. Lancet 1971;1:763-6.

12 MacCuish AC. Childhood diabetes and other endocrine/ autoimmune diseases. In: Childhood and adolescent diabetes. London: Chapman and Hall, 1994; pp 385-95.

13 Riley WJ, Maclaren NK, Lezotte DC, Spillar RP, Rosenbloom AL. Thyroid autoimmunity in insulin-dependent diabetes mellitus: the case for routine screening. $f$ Pediatr 1981;98:350-4.

14 Kong MF, Jeffcoate W. Eighty-six cases of Addison's disease. Clin Endocrinol 1994;41:757-61.

15 Riley WJ, Maclaren NK, Neufeld M. Adrenal autoantibodies and Addison disease in insulin dependent diabetes mellitus. F Pediatrics 1980;97:191-5.

16 Betterle C, Zanette F, Pedini B, et al. Clinical and subclinical organ specific autoimmune manifestations in type 1 (insulin dependent) diabetic patients and their first degree relatives. Diabetologia 1984;26:431-6.

\section{Images in medicine}

\section{Spontaneous bilateral rupture of biceps tendons}

A 59-year-old man was diagnosed to have Crohn's colitis and was started on a large dose of steroids. Six weeks after starting the treatment he developed spontaneous rupture of the long head of the right biceps tendon. Two weeks later he also had spontaneous rupture of the long head of the left biceps tendon (figure).

Spontaneous tendon rupture has been reported in association with various medical conditions including diabetes, chronic renal failure, gout, hyperparathyroidism, systemic lupus erythematosus, rheumatoid arthritis, and fluroquinolone therapy. ${ }^{1}$ The tendons most frequently affected are quadriceps, Achilles and patellar. Local corticosteroid injections can cause spontaneous rupture of tendons but it is rare following oral steroid therapy and limited to case reports. ${ }^{2-4}$ Spontaneous rupture of biceps tendon is very rare and the bilateral involvement has not been reported before. Although the steroids may be the most probable cause of the spontaneous rupture of tendons in our patient, previous history of inguinal hernia suggesting reduction of tensile strength in connective tissue, hypothyroidism, and his medications for hypertension (amlodipine and diltiazem) could have also contributed to this rare complication.

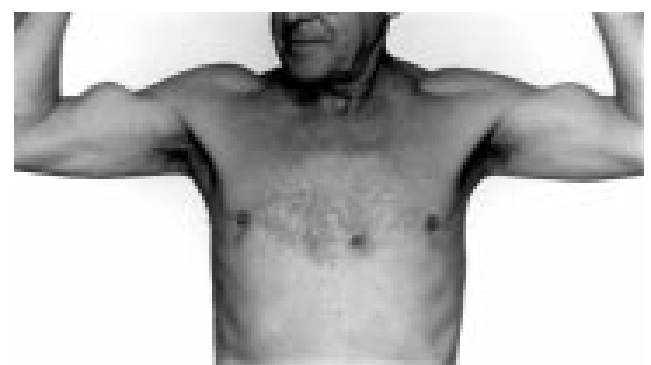

Figure Photograph of the patient, reproduced with his permission

\section{S MANJUNATH \\ D B TRASH \\ Department of Gastroenterology, Manor Hospital, \\ Walsall WS2 9PS UK}

Accepted 22 March 1999

Correspondence to Dr S Manjunath, 3 Warrens Croft, Walsall WS5 3JX, UK

1 Lauzon C, Carette S, Mathon G. Multiple tendon rupture at unusual sites in rheumatoid arthritis. 7 Rheumatol unusual sites

2 Smaill GB. Bilateral rupture of Achilles tendons. BMF $1961 ; 1657-8$.

3 Melmed EP. Spontaneous bilateral rupture of the calcaneal tendons during steroid therapy. F Bone foint Surg 1965;47B: $104-5$.

4 Liow RY, Tavares S. Bilateral rupture of quadriceps tendons associated with anabolic steroids. Br f Sports Med 1995;29: $77-9$. 